\title{
Preventing stroke in atrial fibrillation patients - clinical utility of oral anticoagulants
}

\author{
This article was published in the following Dove Press journal: \\ Journal of Blood Medicine \\ II April 2012 \\ Number of times this article has been viewed
}

\author{
Manish B Jhawar \\ Greg Flaker \\ University of Missouri, Division \\ of Cardiovascular Medicine, \\ Columbia, Missouri, USA
}

Correspondence: Manish B Jhawar Fellow in Cardiovascular Medicine, University of Missouri, Columbia, One Hospital Drive, Columbia, MO 65212, USA

$\mathrm{Tel}+\mathrm{I} 5738828788$

Fax + I 573884322 I

Email jhawarm@health.missouri.edu

\begin{abstract}
Atrial fibrillation is the most common of the cardiac arrhythmias and is associated with high risk of stroke and systemic thromboembolism. Prevention of these complications is therefore a major component of clinical management in patients with this rhythm disorder. The choice of antithrombotic therapy in any given patient depends on his or her risk profile and needs to be carefully balanced against the risk of bleeding. In this review we discuss the pathophysiology of thrombogenesis in atrial fibrillation, risk factors for systemic thromboembolism in atrial fibrillation, patient risk stratification modules both for systemic thromboembolism and the risk of bleeding, current antithrombotic therapy strategies, clinicoepidemiological evidence that led to their evolvement, the challenges that plague them, recent developments in the field and how they could possibly affect our future clinical decision making.
\end{abstract}

Keywords: atrial fibrillation, systemic thromboembolism, thromboembolism, vitamin $\mathrm{K}$ antagonists, oral anticoagulants

\section{Introduction}

Atrial fibrillation (AF) is the most common cardiac arrhythmia encountered in the clinical settings. The Framingham Heart Study showed the lifetime risk of AF for adults older than 40 years is $26 \%$ for men and $23 \%$ for women. ${ }^{1}$ Estimated prevalence of AF in the United States was in excess of 2.2 million in 2001 with an incidence of 70,000 new cases per year. ${ }^{2}$ The prevalence increases steeply as the population ages and per Go et al it is expected to increase upwards of 5.3 million by the year 2050 (Figure 1). ${ }^{2}$ Much of morbidity and mortality associated with AF is a result of systemic thromboembolic (STE) complications, mainly affecting the cerebrovascular system. ${ }^{3}$ The risk of stroke increases five-fold in people with $\mathrm{AF}^{4}$ and is the same across the spectrum of paroxysmal, persistent, and permanent AF. ${ }^{5}$ It has been reported that AF accounts for more than $15 \%$ of all strokes and is the most common cause of ischemic stroke in women older than 75 years of age. ${ }^{6,7}$ It is also known that AF associated strokes are more severe compared to those from other causes, thereby conferring an increased risk of morbidity, mortality, and poor functional outcome. ${ }^{4}$ Therefore, while the treatment of arrhythmia per se is important, measures to prevent STE are equally important if not more, as far as management of patients with this arrhythmia is concerned. Despite in-depth and sound clinical evidence from multiple randomized trials, antithrombotic therapy in AF patients has been challenging. In this review, we plan to discuss some of these challenges, recent developments in the field, and how they could possibly affect our current and future clinical decision-making. 


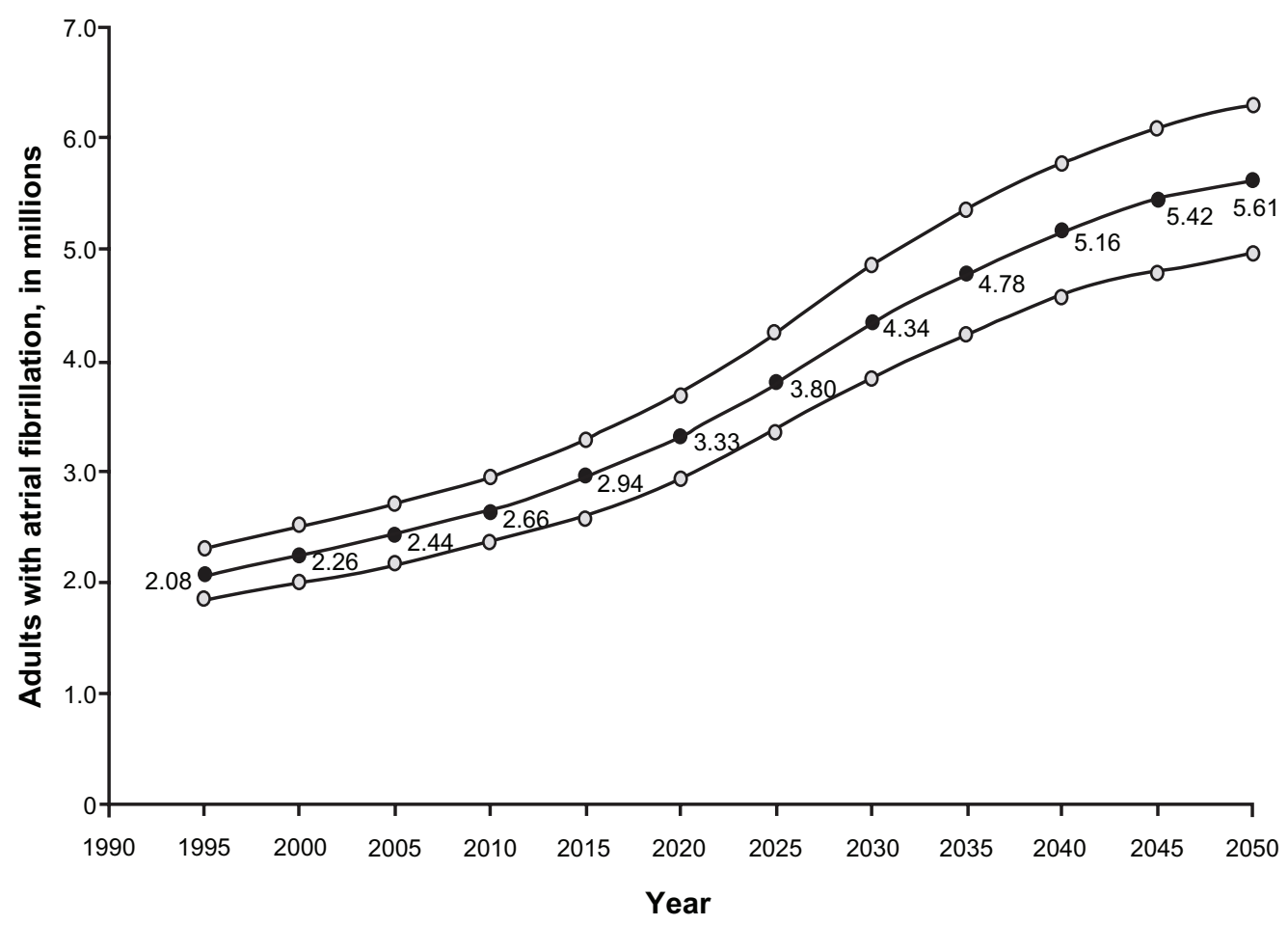

Figure I Projected number of adults with atrial fibrillation in the United States. ${ }^{2}$

\section{Methods}

This review is based on a systematic search of published literature on the topic to date.

\section{AF and stroke Mechanism}

Thromboembolism in AF has been linked to several underlying pathophysiologic mechanisms. These mechanisms involve flow abnormalities as evidenced by "stasis" mainly in the left atrial appendage, the most common site of thrombus formation in patients with $\mathrm{AF}^{8}$ Endomyocardial dysfunction/ disruption caused by progressive dilation of the left atrium in patients with $\mathrm{AF}$, as well as abnormalities of blood constituents and inflammatory and growth factor abnormalities, are thought to result in a substrate for thrombosis. ${ }^{9}$ Due to a combination of these factors, AF patients are at higher risk of developing thromboembolic complications even when in sinus rhythm. ${ }^{10}$

\section{Risk factors for thromboembolism in AF}

Currently reported clinical and echocardiographic risk factors for increased risk of thromboembolism in AF patients have been mainly derived from cohort data and non-warfarin arms of older clinical trials. While the list of these risk factors is long, it only includes those which were documented in the studies, leaving out other potential ones which were not systematically studied and have been reported in various contemporary studies since. ${ }^{11}$ Two recent systematic reviews reviewed all the reported risk factors and identified commonly accepted factors. ${ }^{12,13}$ The list included: prior history of stroke/transient ischemic attack (TIA)/ thromboembolism, advanced age, hypertension, diabetes, structural heart disease, heart failure, and/or systolic dysfunction. While these risk factors help clinicians to determine the individual risk of their patients, there are some caveats and inconsistencies that need to be considered. Age is not a "yes/no" phenomenon as the risk of thromboembolism increases with increasing age. Hypertension as a risk factor in most of the older trials was either uncontrolled hypertension or use of antihypertensive medications, whether or not medically controlled hypertension poses an equal risk of thromboembolism is not known. Also, heart failure mainly referred to systolic heart failure and risk posed by heart failure with preserved systolic function is not reported and hence, not known. ${ }^{11}$

\section{Risk stratification}

As reported in the aforementioned systematic reviews, stroke risk in $\mathrm{AF}$ patients is not homogenous. It varies significantly based on the presence or absence of certain high-risk features 
and a combination thereof. Due to the heterogeneous nature of stroke risk and bleeding complications associated with antithrombotic therapies several risk stratification models (RSMs) have been proposed over the years. ${ }^{12}$ While the earlier RSMs artificially categorized risk into low, moderate, and severe, the more recent ones have opted for a point-based system, realizing that the risk of thromboembolism in AF is a continuum. The most widely used, easy to remember, and most validated of these models is the CHADS2 score, which evolved from the Stroke Prevention in Arial Fibrillation (SPAF) investigators criteria. ${ }^{14} \mathrm{CHADS} 2$, which stands for Congestive heart failure, Hypertension, Age $\geq 75$ years, Diabetes, and Stroke, assigns 1 point each to the first four and 2 points to the history of stroke or TIAs. Studies have validated that the risk of thromboembolic events increases proportionally to the increase in the CHADS2 score (Table 1). ${ }^{14-16}$ Furthermore, treatment with oral anticoagulation (OAC) therapy reduces the risk of thromboembolism for all except those with a CHADS2 score of " 0 " where the bleeding risk outweighed the benefits. ${ }^{15}$ Despite being widely used CHADS2 scoring system has been criticized. First, the ability of CHADS2 score to predict thromboembolic risk in patients with $\mathrm{AF}$ is limited and comparable to other previously described RSMs. ${ }^{17}$ Second, it doesn't take into consideration other stroke risk factors/stroke risk modifiers like female gender, age 65-75 years, and history of vascular disease, that need to be considered for a more comprehensive stroke risk assessment. Third, it categorizes large numbers of people into "moderate risk" with a score of "1," which per societal guidelines up until recently could be treated with either aspirin or vitamin $\mathrm{K}$ antagonists (VKAs). ${ }^{3}$ The third point seems a little discomforting in light of reports showing that therapy with VKAs is superior to antiplatelet therapy in patients with "moderate risk" with no increased risk of bleeding, ${ }^{18}$ and that antiplatelet prescriptions are not always associated with lower adverse events. ${ }^{19}$ Fourth, the

Table I CHADS2 score and stroke rate r-16 $^{4}$

\begin{tabular}{ll}
\hline Score (points) & $\begin{array}{l}\text { Adjusted stroke rate (\% per year) } \\
\text { with 95\% confidence interval }\end{array}$ \\
\hline 0 & $1.9(1.2-3.0)$ \\
1 & $2.8(2.0-3.8)$ \\
2 & $4.0(3.1-5.1)$ \\
3 & $5.9(4.6-7.3)$ \\
4 & $8.5(6.3-11.1)$ \\
5 & $12.5(8.2-17.5)$ \\
6 & $18.2(10.5-27.4)$ \\
\hline
\end{tabular}

Notes: CHADS2 - congestive heart failure; hypertension; age $\geq 75$; diabetes mellitus; stroke (doubled).
CHADS2 score does not incorporate information obtained from cardiac imaging with transesophageal echocardiography (ECHO) - left atrial appendage thrombus, complex aortic plaque, spontaneous ECHO contrast, and reduced left atrial appendage velocities, which have all been shown to be independent predictors of stroke and thromboembolism in AF patients. ${ }^{20}$ To deal with some of these drawbacks a new RSM model has been proposed called the Birmingham 2009 and NICE schema with an acronym CHA2DS2-VASc. ${ }^{17}$ CHA2DS2-VASc score stands for: Congestive heart failure, Hypertension, Age $\geq 75$ years, Diabetes, Stroke/TIA, Vascular disease, Age 65-75 years, and Sex category (female gender). It assigns 2 points each to age $\geq 75$ years and history of stroke/ TIA and 1 point each to the rest for a total possible score of 9 points (Table 2). When applied to a real world AF cohort of patients from the European Heart Survey, CHA2DS2-VASc fared marginally better than CHADS2 (c statistic of 0.606 versus 0.586). However, compared to the CHADS2 score it categorized low risk patients much better (event rate of 0 versus $1.4 \%$ ), the numbers, however, were low. The rate of thromboembolic events increased in proportion to the CHA2DS2-VASc score (Table 3). ${ }^{21}$

\section{Clinical utility of antithrombotic therapy in patients with AF}

Extensive clinical data from multiple trials have provided enough evidence for the use of antithrombotic therapy in AF patients both for primary and secondary prevention of stroke and thromboembolic events.

\section{Adjusted dose VKAs therapy versus placebo or control}

Six large randomized trials published between 1989 and 1992 , AFASAK $1,{ }^{22}$ BAATAF, ${ }^{23}$ SPAF $1,{ }^{24}$ CAFA, ${ }^{25}$ SPINAF, ${ }^{26}$ and $\mathrm{EAFT},{ }^{27}$ evaluated the role of adjusted dose VKAs against placebo in the prevention of stroke/thromboembolism

Table 2 CHA2DS2-VASc score ${ }^{17}$

\begin{tabular}{ll}
\hline Risk factor & Score \\
\hline Congestive heart failure/LV dysfunction & $\mathrm{I}$ \\
Hypertension & $\mathrm{I}$ \\
Age $>75$ & 2 \\
Diabetes mellitus & $\mathrm{I}$ \\
Stroke/TIA/thromboembolism & 2 \\
Vascular disease* & $\mathrm{I}$ \\
Age 65-74 & $\mathrm{I}$ \\
Sex category (ie, female sex) & $\mathrm{I}$ \\
Maximum score & 9 \\
\hline
\end{tabular}

Note: *Prior myocardial infarction; peripheral artery disease; aortic plaque. Abbreviations: LV, left ventricular; TIA, transient ischemic attack. 
Table 3 CHA2DS2-VASc score and stroke rate ${ }^{21}$

\begin{tabular}{ll}
\hline Score (points) & $\begin{array}{l}\text { Adjusted stroke } \\
\text { rate (\% per year) }\end{array}$ \\
\hline 0 & 0 \\
1 & 1.3 \\
2 & 2.2 \\
3 & 3.2 \\
4 & 4.0 \\
5 & 6.7 \\
6 & 9.8 \\
7 & 9.6 \\
8 & 6.7 \\
9 & 15.2 \\
\hline
\end{tabular}

Notes: CHA2DS2-VASc - congestive heart failure/left ventricular dysfunction; hypertension; age $\geq 75$; diabetes mellitus; stroke/transient ischemic attack/ thromboembolism; vascular disease (prior myocardial infarction, peripheral artery disease, aortic plaque); age 65-74; sex category (female sex).

in patients with non-valvular AF. All except the EAFT trial were primary prevention trials. According to a meta-analysis of these trials, adjusted dose VKAs were associated with $64 \%$ relative risk (RR) reduction of all strokes compared to placebo conferring an absolute risk reduction of $2.7 \%$ per year in the primary prevention group and $8.4 \%$ per year in the secondary prevention group. The RR reduction was higher (67\%) when only ischemic strokes were considered. The results were similar for varying severities of stroke, disabling versus non-disabling. Adjusted dose VKAs were associated with reduction in all-cause mortality by $26 \%{ }^{28}$

\section{Antiplatelet therapy versus placebo or control}

Eight randomized trials published between 1989 and 2006, AFASAK I, ${ }^{22}$ SPAF I ${ }^{24}$ EAFT, ${ }^{27}$ ESPS $I I,{ }^{29}$ LASAF, ${ }^{30}$ UK-TIA, ${ }^{31}$ JAST, ${ }^{19}$ and SAFT, ${ }^{32}$ compared antiplatelet therapy mainly comprising of aspirin versus placebo or no treatment for primary and/or secondary prevention of strokes in AF patients. The aspirin dose in these trials varied from $50 \mathrm{mg}$ to $1300 \mathrm{mg}$ per day. Systematic analysis of the trials showed that aspirin use is associated with a $19 \%$ RR reduction of strokes with an absolute risk reduction of $0.8 \%$ per year in the primary and $2.5 \%$ per year in the secondary prevention trials. Available data from four of these trials showed that aspirin was associated with a $13 \%$ reduction in disabling strokes and a $29 \%$ reduction in non-disabling strokes. When only ischemic strokes were looked at, aspirin use resulted in a $22 \% \mathrm{RR}$ of strokes. ${ }^{28} \mathrm{~A}$ large part of the beneficial effect of aspirin noted in this meta-analysis is driven by SPAF I trial results which showed that aspirin $325 \mathrm{mg}$ use was associated with a $42 \%$ RR reduction of strokes when compared with placebo. The trial, however, showed internal heterogeneity in the warfarin eligible ( $R R$ reduction of 94\%) versus the non-warfarin eligible patients (RR reduction of $8 \%$ ). ${ }^{24}$ In the Japanese Atrial Fibrillation Stroke Trial, use of aspirin in people with lone AF was associated with increased primary outcomes (3.1\% versus $2.4 \%$ per year) with a slightly increased, although statistically non-significant risk of increased major bleeds. ${ }^{19}$

\section{VKAs versus antiplatelet therapy}

Warfarin or other oral VKAs have been compared with varying doses of aspirin alone in nine randomized trials: AFASAK I, ${ }^{22}$ EAFT, ${ }^{27}$ SPAF II, ${ }^{33}$ AFASAK II, ${ }^{34}$ PATAF, ${ }^{35}$ a study by Vemmos et al, ${ }^{36}$ the Chinese ATAFS study, ${ }^{37}$ and WASPO. ${ }^{38}$ Three randomized trials compared warfarin/ oral VKAs with other antiplatelet agents: indobufen in SIFA trial, ${ }^{39}$ triflusal in NASPEAF trial, ${ }^{40}$ and aspirin + clopidogrel in the ACTIVE W trial. ${ }^{41}$ On the basis of these twelve trials, warfarin/oral VKAs were associated with a 37\% RR reduction of strokes compared to antiplatelet agents. ${ }^{28}$ The ACTIVE $\mathrm{W}$ trial showed that therapy with VKAs was superior to aspirin + clopidogrel combination therapy (RR reduction by $40 \%$ ) and was associated with significantly lower risk of bleeding. ${ }^{41}$ The ACTIVE-A arm of the trial showed that aspirin and clopidogrel combination therapy was superior to monotherapy with aspirin $(28 \% \mathrm{RR}$ of strokes), in those deemed unsuitable for VKA therapy. ${ }^{42}$ Major bleeding with the combination therapy was, however, noted to be high $(2.0 \%$ versus $1.3 \%$ per year).

\section{Combination VKAs and antiplatelet therapy}

Since the combination of anticoagulant and antiplatelet agents improved outcomes in patients with acute coronary syndrome, ${ }^{43}$ it was intuitive to think that the same would apply to patients with AF with high-risk features. However, a meta-analysis by Dentali et al which looked at several studies with various indications for VKAs, concluded that combination therapy with oral VKAs and antiplatelet agents reduced thromboembolic complications only in patients with mechanical heart valves. There was no difference in risk of thromboembolism in patients with AF with the combination therapy (odds ratio $0.99,95 \%$ confidence interval $0.47-2.07$ ). There was no difference in all-cause mortality with VKAs alone versus VKAs plus antiplatelet therapy (odds ratio $0.98,95 \%$ confidence interval $0.77-1.25$ ), however, there was a significant increase in bleeding risk with the combination therapy (odds ratio 1.43, 95\% confidence interval $1.00-2.02) .^{44}$ 


\section{Bleeding risk}

It is evident from the above discussion that OAC therapy with adjusted dose VKAs is far superior to aspirin/antiplatelet agents in reducing thromboembolic events and all-cause mortality in patients with AF. This benefit, however, came at a price of increased bleeding risk, especially the dreaded complication of intracranial hemorrhage. Systematic review of the trials mentioned above showed that the risk of intracranial bleeds more than doubled in patients on adjusted dose VKAs compared to aspirin/antiplatelet agents. The absolute increase in risk was, however, small at $0.2 \%$ per year. ${ }^{28}$ These findings were, however, challenged by two recent trials, which showed either no difference in the risk of major bleeds (BAFTA) ${ }^{45}$ or even reduced rate of major bleeds (WASPO) ${ }^{38}$ with adjusted dose VKAs compared to aspirin. These results could reflect lower anticoagulation intensity, more careful dosing, or better control of hypertension in OAC patients in the contemporary settings. ${ }^{11}$

Given the increased risk of bleeding with antithrombotic therapies, it is generally perceived that a bleeding risk assessment should be performed in all AF patients before they are prescribed VKAs or antiplatelet therapy. ${ }^{46}$ Several RSMs have been proposed to calculate the bleeding risk in patients on OAC therapy with VKAs over the years. ${ }^{47}$ These schemes either did not focus on AF patients, ${ }^{48,49}$ looked at only a specific cohort of AF patients, ${ }^{50}$ or incorporated risk factors that are not routinely available. ${ }^{51}$ Hence, none of them have been widely validated, commonly used, or recommended in AF management guidelines. Pisters et al proposed a new schema called the HAS-BLED score, using the real world AF patients from the European Heart Survey ${ }^{47}$ The score, which assigns 1 point each for Hypertension, Abnormal liver and/or renal function, Stroke history, Bleeding history or predisposition, Labile international normalized ratio [INR], Elderly (age $>65$ ), and Drugs/alcohol usage, for a total possible score of 9 points (Table 4), showed an increase in the annual bleeding rate with an increasing score in the derivation cohort. ${ }^{47}$ The HAS-BLED score showed better predictive accuracy compared to the previously proposed scores in a validation study performed by authors on the SPORTIF III and V trial patients. ${ }^{52}$ Since it is easy to remember, uses readily available clinical parameters, and fares better in terms of predictive accuracy compared to the other available bleeding RSMs, the European Society of Cardiology has incorporated the HAS-BLED score in their current AF management guidelines. They recommend that a score of $\geq 3$ would indicate "high risk," and that some caution and regular review of the patient would be needed
Table 4 HAS-BLED bleeding risk score ${ }^{47}$

\begin{tabular}{lll}
\hline Letter & Clinical characteristic & Points \\
\hline $\mathrm{H}$ & $\begin{array}{l}\text { Hypertension } \\
\text { Abnormal renal and liver function } \\
\mathrm{A}\end{array}$ & $\mathrm{I}$ \\
$\mathrm{(I}$ point each) & or 2 \\
$\mathrm{~S}$ & Stroke & $\mathrm{I}$ \\
$\mathrm{B}$ & Bleeding & $\mathrm{I}$ \\
$\mathrm{L}$ & Labile INRs & $\mathrm{I}$ \\
$\mathrm{E}$ & Elderly (age $>65)$ & $\mathrm{I}$ \\
$\mathrm{D}$ & Drugs or alcohol (I point each) & I or 2 \\
& & Maximum score of 9 \\
\hline
\end{tabular}

Notes: Hypertension, systolic blood pressure $>160 \mathrm{mmHg}$; abnormal kidney function, presence of chronic dialysis or renal transplantation or serum creatinine $\geq 200 \mathrm{mmol} / \mathrm{L}$; abnormal liver function, chronic hepatic disease (eg, cirrhosis) or biochemical evidence of significant hepatic derangement (eg, bilirubin $>2 \times$ upper limit of normal, in association with aspartate aminotransferase/alanine aminotransferase/alkaline phosphatase $>3 \times$ upper limit normal, etc); bleeding, previous bleeding history and/or predisposition to bleeding, eg, bleeding diathesis, anaemia, etc; labile INRs, unstable/high INRs or poor time in therapeutic range (eg, $<60 \%$ ); drugs/alcohol use, concomitant use of drugs, such as antiplatelet agents, non-steroidal anti-inflammatory drugs, or alcohol abuse, etc.

Abbreviation: INR, international normalized ratio.

following the initiation of antithrombotic therapy, whether with VKAs or aspirin. ${ }^{11}$

Since the publication of the HAS-BLED score, another simple and easy to use bleeding risk stratification score has been proposed and validated by the investigators of the ATRIA study. ${ }^{53}$ The ATRIA hemorrhage risk score includes five commonly available clinical parameters: anemia ( 3 points), severe renal disease ( 3 points), age $\geq 75$ years ( 2 points), prior bleeding (1 point), and hypertension (1 point; Table 5). The score was derived and validated in a large cohort of AF patients enrolled and followed in Kaiser Permanente, a large integrated health care system in Northern California, USA. The hemorrhage rates increased as the score increased from $0.4 \%$ per year in patients with a score of " 0 " to $17.3 \%$ per year in those with a score of " 10 ". When collapsed into three categories, the hemorrhage rates were $0.8 \%$ per year in the low risk (score $0-3$ ), $2.6 \%$ per year in the intermediate

Table 5 ATRIA hemorrhage risk score ${ }^{53}$

\begin{tabular}{ll}
\hline Clinical characteristic & Score \\
\hline Anemia* & 3 \\
Severe renal disease** & 3 \\
Age $>75$ years & 2 \\
Previous bleeding & $\mathrm{I}$ \\
Hypertension & $\mathrm{I}$ \\
Risk category & Maximum score of 10 \\
Low & \\
Intermediate & $0-3$ \\
High & 4 \\
\hline
\end{tabular}

Notes: *Hemoglobin $<13 \mathrm{~g} / \mathrm{dL}$ in men and $<12 \mathrm{~g} / \mathrm{dL}$ in women; **estimated glomerular filtration rate, $30 \mathrm{~mL} / \mathrm{min}$ or dialysis-dependent. 
risk (score of 4), and 5.8\% per year in the high-risk groups (score 5-10). When compared to the previously proposed bleeding RSMs, both the continuous and the categorical forms of the ATRIA score did better with a c-index of 0.74 and 0.69 , respectively. ${ }^{53}$

\section{Current recommendations for antithrombotic therapy}

The current recommendations for antithrombotic therapy in patients with AF are based on the presence or absence of risk factors, using either the CHADS2 risk stratification scheme ${ }^{3,54}$ or using both the CHADS2 and CHA2DS2-VASc schemes, ${ }^{11}$ as outlined in Tables 6 and 7.

\section{Limitations of OAC therapy with VKAs}

VKAs produce their antithrombotic effect by preventing the gamma carboxylation of vitamin $\mathrm{K}$ dependent coagulation factors II, VII, IX, and X. ${ }^{55}$ They have a narrow therapeutic window demonstrating an increased risk of stroke at lower levels of anticoagulation (INR $<2$ ) and higher incidence of intracranial bleeds with INR $>3$ (Figure 2). ${ }^{56,57} \mathrm{VKAs}$ also have an unpredictable pharmacologic profile in different patients, based on genetic factors and multiple food and drug interactions. ${ }^{55}$ To balance the risk of stroke versus the risk of bleeding, and to account for varying pharmacokinetics and pharmacodynamics, patients on VKAs require closer monitoring with frequent dose adjustments, which is challenging both for the clinicians and the patients in the real world. ${ }^{58,59}$ VKAs have a slower onset and offset of action making bridging difficult when patients need to be off OAC therapy for a procedure. Hence, despite proven clinical utility in primary and secondary prevention of strokes in AF patients, adjusted dose VKA therapy has been underutilized. Reported estimates of VKA use amongst eligible AF patients varies from $10 \%-80 \%$ depending on the population group studied, and the use amongst the eligible elderly patients has been consistently reported to be low. ${ }^{60}$ Due to the above stated impediments, even in patients who are on therapy with VKAs, the measures of quality anticoagulation therapy, namely time spent in therapeutic range with INR between two to three has been at best sub-optimal, $\sim 60 \%$ in the settings of clinical trial and $\sim 50 \%$ in the real world. ${ }^{61}$

The limitations of VKAs have long been felt in the scientific community combined with a vigorous effort to look for novel anticoagulation agents that would overcome the shortcomings of the oral VKA agents. An ideal agent would have the following characteristics: orally administrable; wide therapeutic window; fixed dose with predictable pharmacologic profile, and few drug/food interactions obviating the need for closer monitoring. ${ }^{62}$ Several targets have been recognized in the coagulation pathway for development of novel oral/parenteral anticoagulants (Figure 3). ${ }^{63}$ Some of these went into phase III clinical trials and are discussed in the sections below.

\section{Oral direct thrombin inhibitors}

Oral direct thrombin inhibitors bind directly to thrombin in the final step of the coagulation pathway. This prevents formation of fibrin, thrombin mediated activation of Factors V, VII, XI, and XII, and thrombin induced platelet aggregation. ${ }^{62}$ Several oral direct thrombin inhibitors have undergone

Table 6 ACC/AHA/ESC 2006 Guidelines $^{3}$

\begin{tabular}{|c|c|c|}
\hline High-risk factors & Moderate-risk factors & Less validated or weaker risk factors \\
\hline Previous stroke, TIA, or embolism & Age greater than or equal to 75 years & Female gender \\
\hline Mitral stenosis & Hypertension & Hypertension Age $65-74$ years \\
\hline \multirow[t]{3}{*}{ Prosthetic heart valve } & Heart failure & Coronary artery disease \\
\hline & LV ejection fraction $35 \%$ or less & Thyrotoxicosis \\
\hline & Diabetes mellitus & \\
\hline \multicolumn{3}{|l|}{ Recommendations } \\
\hline No risk factors & \multicolumn{2}{|l|}{ Aspirin, 81-325 mg daily } \\
\hline One moderate-risk factor & \multicolumn{2}{|l|}{$\begin{array}{l}\text { Aspirin, } 81-325 \mathrm{mg} \text { daily, or warfarin } \\
\text { (INR } 2.0 \text { to } 3.0 \text {, target } 2.5 \text { ) }\end{array}$} \\
\hline Any high-risk factor or more than & \multicolumn{2}{|l|}{ Warfarin (INR 2.0 to 3.0 , target 2.5 ) } \\
\hline I moderate-risk factor & \multicolumn{2}{|l|}{ (If mechanical valve, target INR greater than 2.5 ) } \\
\hline \multicolumn{3}{|c|}{ 20I I AACF/AHA/HRS focused update ${ }^{54}$} \\
\hline \multicolumn{3}{|c|}{$\begin{array}{l}\text { Dabigatran is useful as an alternative to warfarin for the prevention of stroke and systemic thromboembolism in patients with paroxysmal to } \\
\text { permanent atrial fibrillation and risk factors for stroke or systemic embolization who do not have a prosthetic heart valve or hemodynamically } \\
\text { significant valve disease, severe renal failure (creatinine clearance }-15 \mathrm{~mL} / \mathrm{min} \text { ), or advanced liver disease (impaired baseline clotting function) }\end{array}$} \\
\hline
\end{tabular}

Abbreviations: TIA, transient ischemic attack; INR, international normalized ratio. 
Table 7 ESC 2010 Guidelines"

\begin{tabular}{|c|c|c|}
\hline Major risk factors & \multicolumn{2}{|c|}{ Clinically relevant non-major risk factors } \\
\hline Previous stroke, TIA, or embolism & \multicolumn{2}{|c|}{ Heart failure or moderate to severe systolic dysfunction (eg, LVEF $\leq 40 \%$ ) } \\
\hline \multirow[t]{5}{*}{ Age greater than or equal to 75 years } & \multicolumn{2}{|c|}{ Hypertension } \\
\hline & \multicolumn{2}{|l|}{ Diabetes } \\
\hline & \multicolumn{2}{|l|}{ Female sex } \\
\hline & \multicolumn{2}{|l|}{ Age $65-74$ years } \\
\hline & \multicolumn{2}{|l|}{ Vascular disease $^{+}$} \\
\hline \multicolumn{3}{|l|}{ Recommendations } \\
\hline Risk category & CHA2DS2-VASc score & Recommended therapy \\
\hline $\begin{array}{l}\text { One major or } \geq 2 \text { clinically relevant } \\
\text { non-major risk factors }\end{array}$ & $\geq 2$ & Oral anticoagulation therapy* for goal INR 2-3 \\
\hline I clinically relevant non-major & 1 & Either oral anticoagulation therapy* for goal INR of 2-3 or aspirin \\
\hline risk factor & & 75-325 mg daily. Preferred: oral anticoagulation therapy rather than aspirin \\
\hline \multirow[t]{2}{*}{ No risk factor } & 0 & Either aspirin 75-325 mg daily or no antithrombotic therapy. \\
\hline & & Preferred: no antithrombotic therapy rather than aspirin \\
\hline
\end{tabular}

Notes: +Prior myocardial infarction, peripheral artery disease, aortic plaque; *dabigatran may be considered as an alternative where oral anticoagulation therapy is appropriate. Hypertension, Age $\geq 75$, Diabetes mellitus, Stroke/Transient ischemic attack/Thromboembolism, Vascular disease, Age 65-74, Sex category (female sex).

Abbreviations: TIA, transient ischemic attack; LVEF, left ventricular ejection fraction; INR, international normalized ratio; CHA2DS2-VASc, congestive heart failure/ Left ventricular dysfunction.

clinical development and two have been studied for stroke prevention in AF patients - ximelagatran and dabigatran.

Ximelagatran was one of the first oral direct thrombin inhibitors to be studied in phase III clinical trials for stroke and STE prevention in AF patients. The drug showed promise in terms of being non-inferior to warfarin with a better bleeding profile. ${ }^{64,65}$ However, several studies showed increased hepatotoxicity and adverse cardiovascular events with the $\operatorname{drug}^{64-67}$ and hence, it was withdrawn from the market and further development stopped in 2006.

The oral direct thrombin inhibitor dabigatran was compared to warfarin in the RE-LY trial, ${ }^{68}$ which had a prospective, randomized, open, blinded-endpoint evaluation

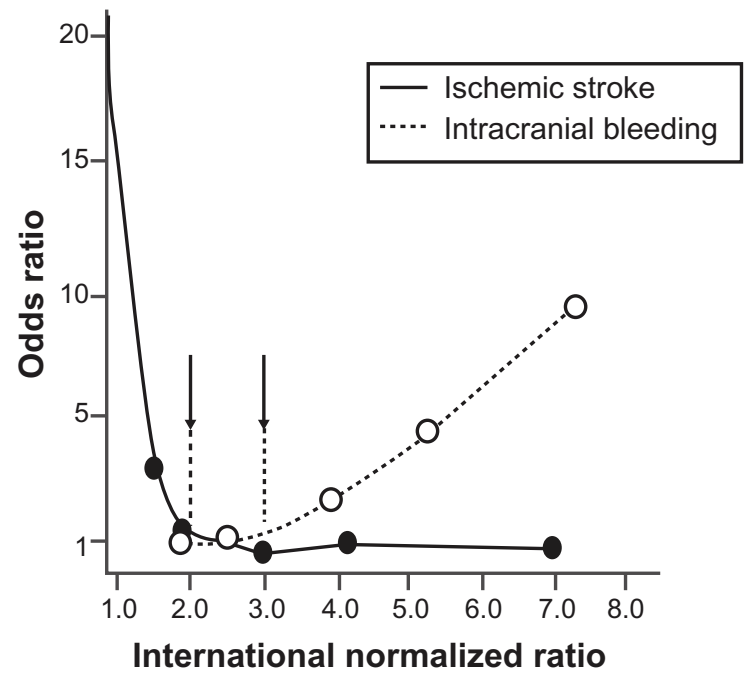

Figure 2 Ischemic stroke and intracranial bleeding in relation to intensity of anticoagulation. ${ }^{56,57}$ design. Dabigatran $110 \mathrm{mg}$ twice a day was non-inferior to warfarin for the primary endpoint of stroke and systemic embolism and was associated with $20 \%$ fewer major bleeds. On the other hand, $150 \mathrm{mg}$ twice-daily dose of dabigatran showed superiority compared with warfarin with a 35\% less stroke and STE and there was no significant difference to warfarin in terms of major bleeds. Both doses of dabigatran had significantly fewer life-threatening major bleeds and significantly fewer intracranial hemorrhages compared with warfarin. The $150 \mathrm{mg}$ arm of the trial showed increased major gastrointestinal bleeds, which was statistically significant. The authors of the trial attributed this to the acidic milieu required for dabigatran absorption and the drug delivery system that comprises of drug coated pellets with a tartaric acid core. The actual reason, however, remains unknown and needs further investigation. There was also a numerical but nonstatistically significant increase in myocardial infarction events in dabigatran-treated patients compared with warfarin. ${ }^{68}$ It is not clear if this is largely an adverse effect of dabigatran or a protective effect of warfarin, which affects multiple coagulation pathways, compared to dabigatran, which only targets thrombin. Similar findings were seen in the SPORTIF III trial, which compared ximelagatran with warfarin, ${ }^{64}$ and the AMADEUS trial that compared idraparinux with warfarin. ${ }^{69}$ However, the SPORTIF V trial that also compared ximelagatran with warfarin did not show this effect, leaving the above explanation uncertain. ${ }^{65}$ Dabigatran is currently approved for usage in stroke prevention in AF patients both in Europe and the United States. 


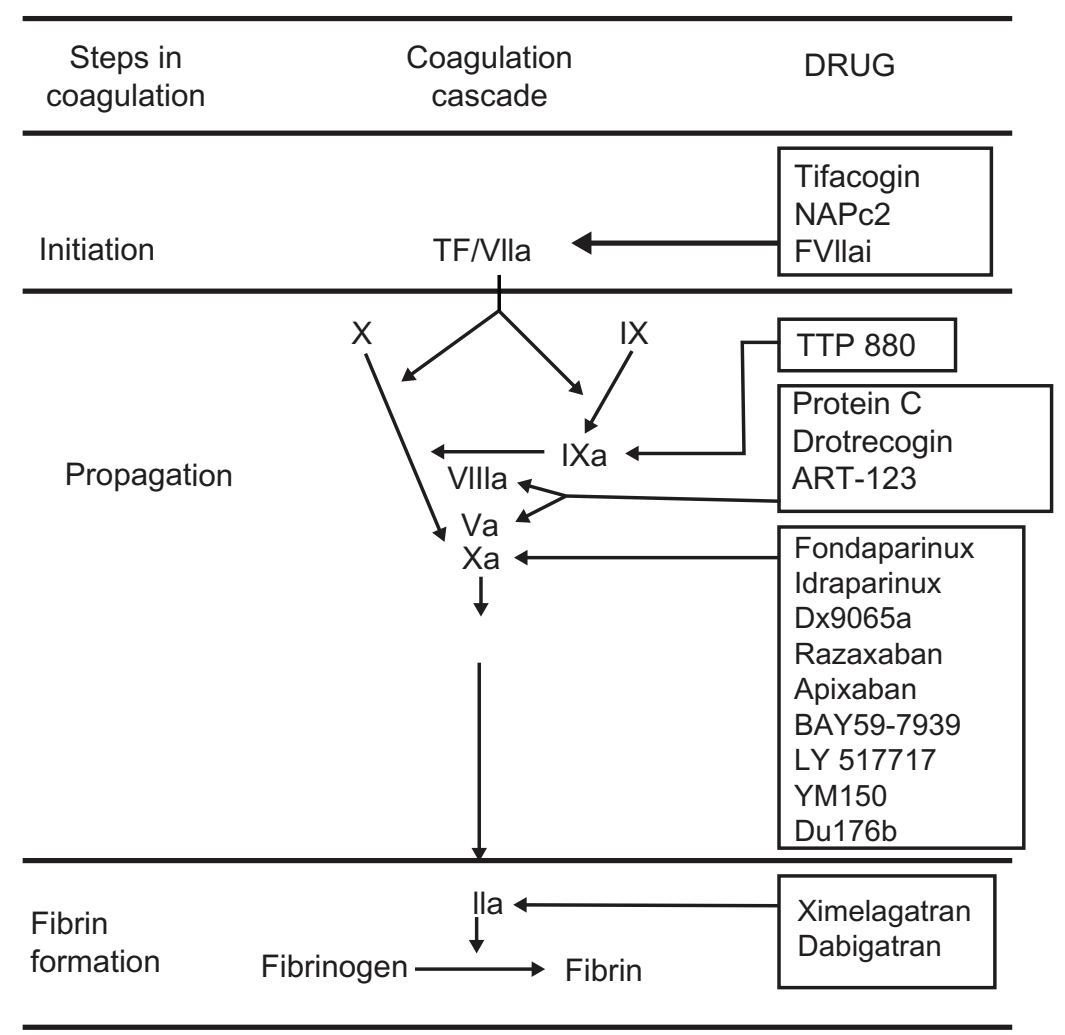

Figure 3 Targets for novel anticoagulants in the coagulation pathway. ${ }^{63}$

\section{Factor Xa (FXa) inhibitors}

FXa inhibitors may block FXa directly by binding to its active site, thereby preventing its interaction with the substrates or indirectly requiring antithrombin as a cofactor. Fondaparinux and idraparinux inhibit FXa indirectly and are administered parenterally, while direct FXa inhibitors are oral agents at various stages of clinical development and include LY517717, YM150, DU-176b, apixaban, betrixaban, and rivaroxaban. ${ }^{62}$ Some of these agents have already been evaluated in phase III clinical trials for prevention of stroke and STE in AF patients and are discussed below.

The AMADEUS trial compared indirect FXa inhibitor idraparinux against adjusted dose VKAs for stroke and STE prevention in AF patients. The trial was stopped after randomization due to excessive clinically relevant bleeding in the idraparinux group. ${ }^{6}$

The AVERROES trial compared direct FXa inhibitor apixaban against aspirin in patients deemed unsuitable for warfarin. This trial was stopped early due to very clear superiority of apixaban over aspirin, demonstrating a 55\% reduction in the primary endpoint of stroke and STE. There was no significant difference between apixaban and aspirin as far as major bleeds and intracranial hemorrhage was concerned. Apixaban was better tolerated than aspirin with a permanent discontinuations rate of $17.9 \%$ per year against $20.5 \%$ per year with aspirin. ${ }^{70}$

ROCKET AF trial was a double-blind, double-dummied design in 14,200 patients, and aimed to achieve non-inferiority when comparing direct FXa inhibitor rivaroxaban against warfarin. The trial did achieve its goal of non-inferiority in the on treatment (hazard ratio $0.79, P<0.001$ ) and intention to treat analysis (hazard ratio $0.88, P<0.001$ ). ${ }^{71}$ The FDA recently approved rivaroxaban for use in prevention of stroke and STE in AF patients.

ARISTOTLE, a double-blind, double-dummy phase III clinical trial, compared direct FXa inhibitor apixaban to warfarin in patients with $\mathrm{AF}$ and at least one additional risk factor for stroke. The primary endpoint was stroke, both ischemic and hemorrhagic stroke, or STE. Apixaban demonstrated a $21 \%$ reduction in stroke or STE $(P 0.01)$, a $31 \%$ reduction in major bleeding $(P<0.01)$, and an $11 \%$ reduction in allcause mortality ( $P$ 0.047). The reduced number of stroke with apixaban was mainly driven by the reduction of hemorrhagic stroke, a 50\% reduction compared with warfarin. On ischemic stroke and uncertain stroke, there was essentially no difference with apixaban compared with warfarin. There was no increase in myocardial infarction; in fact, there was a trend toward a lower rate of myocardial infarction 
differentiating it from the other thrombin-inhibitor trials. ${ }^{72}$ Table 8 compares the main findings of RE-LY, ROCKET AF, and ARISTOTLE trials.

\section{Use of new OACs in clinical practice}

The newer OACs, thrombin inhibitor (dabigatran) and FXa inhibitors (rivaroxaban, apixaban), come close in terms of the ideal properties in oral agents that the scientific community has been looking for. However, there are significant differences in pharmacokinetics and pharmacodynamics of these agents that an astute clinician should be aware of and are outlined in Table $9 .^{73}$

\section{Advantages of the newer agents over VKAs}

The new OACs have faster onset and offset of action compared to VKAs, obviating the need for bridging therapy. They have fixed dosing with predictable anticoagulation effect as opposed to VKAs, whose dosing is variable, requiring frequent coagulation tests and dose adjustment based on INR response. These agents have fewer food and drug interactions when compared to VKAs, meaning fewer dietary and drug precautions for patients. They have specific coagulation enzyme targets, which means low risk for offtarget adverse events.

\section{Disadvantages/concerns with the use of newer agents over VKAs}

Several clinical trials, as discussed above, have now shown that the new OACs, if not better, are as good as VKAs in preventing stroke in patients with AF. We cannot, however, overlook some potential problems with these newer agents. First, most of them have twice a day dosing for the indication of stroke prevention in $\mathrm{AF}$ as compared to once a day dosing with VKAs. How this will affect patient compliance is not known. While infrequent monitoring is a big advantage compared to VKAs, the drawback is that there is no tangible way yet to assess patient adherence, confirm adequacy of treatment, detect overdose/toxicity before it is too late, and last (but not least) a reassurance for the physicians and the patients that the drug is working. Unlike VKAs, most of these new agents are excreted by the kidneys to varying extents $(25 \%-80 \%$; Table 9), which could mean potential for accumulation in renal insufficiency and increased risk of bleeding. Dose adjustment in patients with renal insufficiency will therefore be crucial. All the major clinical trials have shown reduced incidence of intracranial hemorrhages with the newer agents compared to VKAs, bleeding nevertheless still remains an important

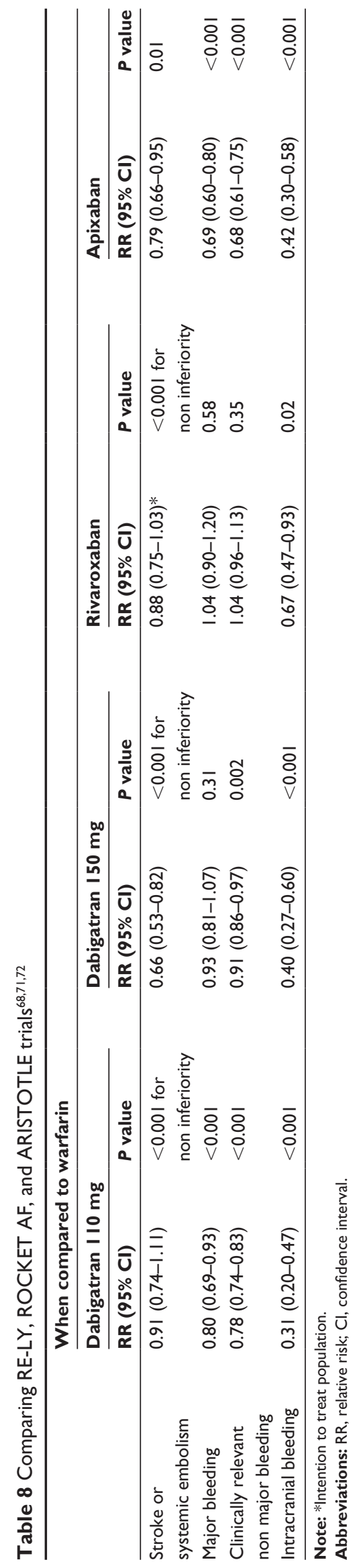


Table 9 Pharmacokinetics and pharmacodynamics of new oral anticoagulant agents ${ }^{73}$

\begin{tabular}{|c|c|c|c|}
\hline & Dabigatran & Rivaroxaban & Apixaban \\
\hline Target & Thrombin & Factor $\mathrm{Xa}$ & Factor $\mathrm{Xa}$ \\
\hline Prodrug & Yes & No & No \\
\hline $\begin{array}{l}\text { Time to peak plasma } \\
\text { concentration (hours) }\end{array}$ & $2.3-2.9$ & $2.5-4.0$ & 5.8 \\
\hline Half-life (hours) & $14-17$ & $5.7-9.2$ & $\sim 12$ \\
\hline Bioavailability & $4 \%-5 \%$ & $60 \%-80 \%$ & $50 \%-85 \%$ \\
\hline Dosing & $\begin{array}{l}\text { Twice a day } \\
\text { (Once a day) }\end{array}$ & $\begin{array}{l}\text { Once a day } \\
\text { (Twice a day) }\end{array}$ & $\begin{array}{l}\text { Twice a } \\
\text { day }\end{array}$ \\
\hline Food interference & $\begin{array}{l}\text { Acidic milieu needed for absorption; } \\
\text { food and drugs increasing stomach/intestine } \\
\mathrm{pH} \text { may reduce absorption }\end{array}$ & $\begin{array}{l}\text { Absorption increased } \\
\text { by food }\end{array}$ & Not known \\
\hline Drug interference & $\begin{array}{l}\text { Moderate. Especially with p-glycoprotein inhibitors } \\
\text { (eg, Verapamil) or inducers (eg, Rifampicin) }\end{array}$ & Low & Low \\
\hline Renal clearance & $80 \%$ & $65 \%$ & $25 \%$ \\
\hline Hepatic clearance & $20 \%$ & $28 \%-35 \%$ & $75 \%$ \\
\hline $\begin{array}{l}\text { Need for dose adjustment } \\
\text { with renal insufficiency }\end{array}$ & Yes & Yes & Possibly \\
\hline Hepatotoxicity & Unknown & Unknown & Unknown \\
\hline $\begin{array}{l}\text { Need for International normalized } \\
\text { ratio monitoring }\end{array}$ & No & No & No \\
\hline
\end{tabular}

concern with the use of these agents. INR monitoring plays a crucial role in a bleeding patient on VKAs, absence of a similar clinical parameter to follow in patients who could bleed on these newer agents is concerning. Another major concern with the use of these newer agents is the lack of a clinically proven antidote. The half-lives of the newer agents vary anywhere from 6 hours to 18 hours (Table 9); lack of an antidote, like vitamin $\mathrm{K}$ therapy for VKAs, could mean continued bleeding for several hours in patients being treated with direct thrombin or FXa inhibitors. Although there are no antidotes currently available that could reverse the effect of the newer agents, fresh frozen plasma and prothrombin complex concentrate could be used in the settings of major bleeds. ${ }^{73}$ In a small study on healthy individuals by Eerenberg et al prothrombin complex concentrate showed immediate and complete reversal of the anticoagulation effect of rivaroxaban but not that of dabigatran. ${ }^{74}$ While agents like prothrombin complex concentrate show a promise, before they are shown to be effective in large clinical trials and are widely available, clinicians will have to use both caution and clinical judgment with the use of the newer agents. Lastly, the newer agents have shown to be safe in the settings of clinical trials, however, their long-term safety when used in the real world is still a concern (and a valid one) until more data is available.

\section{Conclusion}

Prevention of stroke and STE has major implications from the mortality and morbidity perspectives in patients with AF.
Despite overwhelming evidence of its clinical utility in prevention of thromboembolism in AF patients, adjusted dose VKA agents (especially warfarin) have been challenging, leading to underutilization in otherwise at risk and eligible patients. The inadequacy of VKA therapy led to an active search for novel anticoagulant agents targeting different sites in the coagulation pathway. Some of these agents, namely the direct thrombin inhibitor dabigatran, and direct FXa inhibitors (apixaban and rivaroxaban) have recently been tested in phase III clinical trials and have shown promise, heralding an exciting phase in the field of AF and anticoagulation, albeit with cautious optimism. These drugs appear to be non-inferior to warfarin. In fact, some show a trend towards even being superior. The question would be how to use these drugs in patients once they become more readily available. Some of the factors that will play a role in shaping our future clinical decision-making would include the ready availability of laboratory tests to measure the therapeutic effectiveness of these agents; availability of agents that could reverse the effect of these agents when needed; cost effectiveness compared to warfarin; patient preference, especially in case of those who are currently stable on warfarin therapy; safety of use in patients with renal insufficiency or those on dialysis; and safety and effectiveness in patients with mechanical valves. Due to the challenges associated with oral VKA therapy, many eligible Afib patients never get started on an OAC therapy. One possible advantage with the advent of these newer agents is that, it may reduce the 
threshold to start effective OAC therapy in otherwise eligible Afib patients in the primary care settings.

While the CHADS2 score is widely used and most validated of the RSMs, it has been shown to have its own shortcomings. The recently proposed CHA2DS2-VASc score shows promise and could definitely prove to be an important tool in the contentious group of patients with a CHADS2 score of 1 , especially now with the availability of easy to use agents.

Bleeding risk assessment has always been felt to be important when starting AF patients on OAC therapy. While several bleeding RSMs were proposed over the years, none seemed easy to use and easy to remember in general clinical settings. The recently proposed HAS-BLED score and the ATRIA hemorrhage risk score are easy to remember, use readily available clinical parameters, have been validated in real-life AF patients, and could prove to be important tools in clinical decision making as far as AF and OAC therapy is concerned.

\section{Disclosure}

Dr Jhawar has no disclosures to make and reports no conflicts of interest in this work. Dr Flaker has research grants from Boeringer-Ingelheim, Sanofi-Aventis, Bristol-Myers Squibb and Pfizer. He is a consultant for the above companies.

\section{References}

1. Lloyd-Jones DM, Wang TJ, Leip EP, et al. Lifetime risk for development of atrial fibrillation: the Framingham Heart Study. Circulation. 2004;110(9):1042-1046.

2. Go AS, Hylek EM, Phillips KA, et al. Prevalence of diagnosed atrial fibrillation in adults: national implications for rhythm management and stroke prevention: the AnTicoagulation and Risk Factors in Atrial Fibrillation (ATRIA) Study. JAMA. 2001;285(18):2370-2375.

3. Fuster V, Rydén LE, Cannom DS, et al; American College of Cardiology; American Heart Association Task Force; European Society of Cardiology Committee for Practice Guidelines; European Heart Rhythm Association; Heart Rhythm Society. ACC/AHA/ESC 2006 guidelines for the management of patients with atrial fibrillation: full text: a report of the American College of Cardiology/American Heart Association Task Force on practice guidelines and the European Society of Cardiology Committee for Practice Guidelines (Writing Committee to Revise the 2001 guidelines for the management of patients with atrial fibrillation) developed in collaboration with the European Heart Rhythm Association and the Heart Rhythm Society. Europace. 2006;8(9):651-745.

4. Savelieva I, Bajpai A, Camm AJ. Stroke in atrial fibrillation: update on pathophysiology, new antithrombotic therapies, and evolution of procedures and devices. Ann Med. 2007;39(5):371-391.

5. Hart RG, Pearce LA, Rothbart RM, McAnulty JH, Asinger RW, Halperin JL. Stroke with intermittent atrial fibrillation: incidence and predictors during aspirin therapy. Stroke Prevention in Atrial Fibrillation Investigators. J Am Coll Cardiol. 2000;35(1):183-187.

6. Hart RG, Halperin JL. Atrial fibrillation and stroke: concepts and controversies. Stroke. 2001;32(3):803-808.

7. Lip GY, Lim HS. Atrial fibrillation and stroke prevention. Lancet Neurol. 2007;6(11):981-993.
8. Blackshear JL, Odell JA. Appendage obliteration to reduce stroke in cardiac surgical patients with atrial fibrillation. Ann Thorac Surg. 1996;61(2):755-759.

9. Watson T, Shantsila E, Lip GY. Mechanisms of thrombogenesis in atrial fibrillation: Virchow's triad revisited. Lancet. 2009;373(9658): 155-166.

10. Pollick C, Taylor D. Assessment of left atrial appendage function by transesophageal echocardiography. Implications for the development of thrombus. Circulation. 1991;84(1):223-231.

11. European Heart Rhythm Association; European Association for CardioThoracic Surgery. Guidelines for the management of atrial fibrillation: The Task Force for the Management of Atrial Fibrillation of the European Society of Cardiology (ESC). Eur Heart J. 2010;31(19):2369-2429.

12. Hughes M, Lip GY. Stroke and thromboembolism in atrial fibrillation: a systematic review of stroke risk factors, risk stratification schema and cost effectiveness data. Thromb Haemost. 2008;99(2):295-304.

13. Stroke Risk in Altrial Fibrillation Working Group. Independent predictors of stroke in patients with atrial fibrillation: a systematic review. Neurology. 2007;69(6):546-554.

14. Gage BF, Waterman AD, Shannon W, Boechler M, Rich MW, Radford MJ. Validation of clinical classification schemes for predicting stroke: results from the National Registry of Atrial Fibrillation. JAMA. 2001;285(22):2864-2870.

15. Go AS, Hylek EM, Chang Y, et al. Anticoagulation therapy for stroke prevention in atrial fibrillation: how well do randomized trials translate into clinical practice? JAMA. 2003;290(20):2685-2692.

16. Gage BF, van Walraven C, Pearce L, et al. Selecting patients with atrial fibrillation for anticoagulation: stroke risk stratification in patients taking aspirin. Circulation. 2004;110(16):2287-2292.

17. Lip GY, Nieuwlaat R, Pisters R, Lane DA, Crijns HJ. Refining clinical risk stratification for predicting stroke and thromboembolism in atrial fibrillation using a novel risk factor-based approach: the euro heart survey on atrial fibrillation. Chest. 2010;137(2):263-272.

18. Gorin L, Fauchier L, Nonin E, et al. Antithrombotic treatment and the risk of death and stroke in patients with atrial fibrillation and a CHADS2 score $=1$. Thromb Haemost. 2010;103(4):833-840.

19. Sato H. Low-dose aspirin for prevention of stroke in low-risk patients with atrial fibrillation: Japan Atrial Fibrillation Stroke Trial. Stroke. 2006;37(2):447-451.

20. No authors listed. Transesophageal echocardiographic correlates of thromboembolism in high-risk patients with nonvalvular atrial fibrillation. The Stroke Prevention in Atrial Fibrillation Investigators Committee on Echocardiography. Ann Intern Med. 1998;128(8):639-647.

21. Olesen JB, Lip GY, Hansen ML, et al. Validation of risk stratification schemes for predicting stroke and thromboembolism in patients with atrial fibrillation: nationwide cohort study. BMJ. 2011;342:d124.

22. Petersen P, Boysen G, Godtfredsen J, Andersen ED, Andersen B. Placebo-controlled, randomised trial of warfarin and aspirin for prevention of thromboembolic complications in chronic atrial fibrillation. The Copenhagen AFASAK study. Lancet. 1989;1(8631):175-179.

23. No authors listed. The effect of low-dose warfarin on the risk of stroke in patients with nonrheumatic atrial fibrillation. The Boston Area Anticoagulation Trial for Atrial Fibrillation Investigators. $N$ Engl J Med. 1990;323(22):1505-1511.

24. No authors listed. Stroke Prevention in Atrial Fibrillation Study. Final results. Circulation. 1991;84(2):527-539.

25. Connolly SJ, Laupacis A, Gent M, Roberts RS, Cairns JA, Joyner C. Canadian Atrial Fibrillation Anticoagulation (CAFA) Study. J Am Coll Cardiol. 1991;18(2):349-355.

26. Ezekowitz MD, Bridgers SL, James KE, et al. Warfarin in the prevention of stroke associated with nonrheumatic atrial fibrillation. Veterans Affairs Stroke Prevention in Nonrheumatic Atrial Fibrillation Investigators. N Engl J Med. 1992;327(20):1406-1412.

27. No authors listed. Secondary prevention in non-rheumatic atrial fibrillation after transient ischaemic attack or minor stroke. EAFT (European Atrial Fibrillation Trial) Study Group. Lancet. 1993;342(8882): 1255-1262. 
28. Hart RG, Pearce LA, Aguilar MI. Meta-analysis: antithrombotic therapy to prevent stroke in patients who have nonvalvular atrial fibrillation. Ann Intern Med. 2007;146(12):857-867.

29. Diener HC, Cunha L, Forbes C, Sivenius J, Smets P, Lowenthal A. European Stroke Prevention Study. 2. Dipyridamole and acetylsalicylic acid in the secondary prevention of stroke. J Neurol Sci. 1996;143(1-2):1-13.

30. Posada IS, Barriales V. Alternate-day dosing of aspirin in atrial fibrillation. LASAF Pilot Study Group. Am Heart J. 1999;138(1 Pt 1): 137-143.

31. Farrell B, Godwin J, Richards S, Warlow C. The United Kingdom transient ischaemic attack (UK-TIA) aspirin trial: final results. J Neurol Neurosurg Psychiatr. 1991;54(12):1044-1054.

32. Edvardsson N, Juul-Möller S, Omblus R, Pehrsson K. Effects of low-dose warfarin and aspirin versus no treatment on stroke in a medium-risk patient population with atrial fibrillation. J Intern Med. 2003;254(1):95-101.

33. No authors listed. Warfarin versus aspirin for prevention of thromboembolism in atrial fibrillation: Stroke Prevention in Atrial Fibrillation II Study. Lancet. 1994;343(8899):687-691.

34. Gulløv AL, Koefoed BG, Petersen P. Bleeding during warfarin and aspirin therapy in patients with atrial fibrillation: the AFASAK 2 study. Atrial Fibrillation Aspirin and Anticoagulation. Arch Intern Med. 1999;159(12):1322-1328

35. Hellemons BS, Langenberg M, Lodder J, et al. Primary prevention of arterial thromboembolism in non-rheumatic atrial fibrillation in primary care: randomised controlled trial comparing two intensities of coumarin with aspirin. BMJ. 1999;319(7215):958-964.

36. Vemmos KN, Tsivgoulis G, Spengos K, et al. Primary prevention of arterial thromboembolism in the oldest old with atrial fibrillation - a randomized pilot trial comparing adjusted-dose and fixed low-dose coumadin with aspirin. Eur J Intern Med. 2006;17(1):48-52.

37. Hu DY, Zhang HP, Sun YH, Jiang LQ; Antithrombotic Therapy in Atrial Fibrillation Study Group. The randomized study of efficiency and safety of antithrombotic therapy in nonvalvular atrial fibrillation: warfarin compared with aspirin. [Article in Chinese]. Zhonghua Xin Xue Guan Bing Za Zhi. 2006;34(4):295-298.

38. Rash A, Downes T, Portner R, Yeo WW, Morgan N, Channer KS. A randomised controlled trial of warfarin versus aspirin for stroke prevention in octogenarians with atrial fibrillation (WASPO). Age Ageing. 2007;36(2):151-156.

39. Morocutti C, Amabile G, Fattapposta F, et al. Indobufen versus warfarin in the secondary prevention of major vascular events in nonrheumatic atrial fibrillation. SIFA (Studio Italiano Fibrillazione Atriale) Investigators. Stroke. 1997;28(5):1015-1021.

40. Pérez-Gómez F, Alegría E, Berjón J, et al; NASPEAF Investigators. Comparative effects of antiplatelet, anticoagulant, or combined therapy in patients with valvular and nonvalvular atrial fibrillation: a randomized multicenter study. J Am Coll Cardiol. 2004;44(8):1557-1566.

41. Connolly S, Pogue J, Hart R, et al; ACTIVE Writing Group of the ACTIVE Investigators. Clopidogrel plus aspirin versus oral anticoagulation for atrial fibrillation in the Atrial fibrillation Clopidogrel Trial with Irbesartan for prevention of Vascular Events (ACTIVE W): a randomised controlled trial. Lancet. 2006;367(9526):1903-1912.

42. Connolly SJ, Pogue J, Hart RG, et al; ACTIVE Investigators. Effect of clopidogrel added to aspirin in patients with atrial fibrillation. $N E n g J$ Med. 2009;360(20):2066-2078.

43. Eikelboom JW, Hirsh J. Combined antiplatelet and anticoagulant therapy: clinical benefits and risks. JThromb Haemost. 2007;5 Suppl 1: 255-263.

44. Dentali F, Douketis JD, Lim W, Crowther M. Combined aspirin-oral anticoagulant therapy compared with oral anticoagulant therapy alone among patients at risk for cardiovascular disease: a meta-analysis of randomized trials. Arch Intern Med. 2007;167(2):117-124.

45. Mant J, Hobbs FD, Fletcher K, et al; BAFTA Investigators; Midland Research Practices Network (MidReC). Warfarin versus aspirin for stroke prevention in an elderly community population with atrial fibrillation (the Birmingham Atrial Fibrillation Treatment of the Aged Study, BAFTA): a randomised controlled trial. Lancet. 2007;370(9586):493-503.
46. Nieuwlaat R, Capucci A, Lip GY, et al; Euro Heart Survey Investigators. Antithrombotic treatment in real-life atrial fibrillation patients: a report from the Euro Heart Survey on Atrial Fibrillation. Eur Heart J. 2006;27(24):3018-3026.

47. Pisters R, Lane DA, Nieuwlaat R, de Vos CB, Crijns HJ, Lip GY. A novel user-friendly score (HAS-BLED) to assess 1-year risk of major bleeding in patients with atrial fibrillation: the Euro Heart Survey. Chest. 2010;138(5):1093-1100.

48. Beyth RJ, Quinn LM, Landefeld CS. Prospective evaluation of an index for predicting the risk of major bleeding in outpatients treated with warfarin. Am J Med. 1998;105(2):91-99.

49. Kuijer PM, Hutten BA, Prins MH, Büller HR. Prediction of the risk of bleeding during anticoagulant treatment for venous thromboembolism. Arch Intern Med. 1999;159(5):457-460.

50. Shireman TI, Howard PA, Kresowik TF, Ellerbeck EF. Combined anticoagulant-antiplatelet use and major bleeding events in elderly atrial fibrillation patients. Stroke. 2004;35(10):2362-2367.

51. Gage BF, Yan Y, Milligan PE, et al. Clinical classification schemes for predicting hemorrhage: results from the National Registry of Atrial Fibrillation (NRAF). Am Heart J. 2006;151(3):713-719.

52. Lip GY, Frison L, Halperin JL, Lane DA. Comparative validation of a novel risk score for predicting bleeding risk in anticoagulated patients with atrial fibrillation: the HAS-BLED (Hypertension, Abnormal Renal/ Liver Function, Stroke, Bleeding History or Predispostion, Labile INR, Elderly, Drugs/Alcohol Concomitantly) score. J Am Coll Cardiol. 2011; 57(2):173-180.

53. Fang MC, Go AS, Chang Y, et al. A new risk scheme to predict warfarin-associated hemorrhage: The ATRIA (Anticoagulation and Risk Factors in Atrial Fibrillation) Study. J Am Coll Cardiol. 2011;58(4): 395-401.

54. Wann LS, Curtis AB, Ellenbogen KA, et al; American College of Cardiology Foundation/American Heart Association Task Force. $2011 \mathrm{ACCF} / \mathrm{AHA} / \mathrm{HRS}$ focused update on the management of patients with atrial fibrillation (update on Dabigatran): a report of the American College of Cardiology Foundation/American Heart Association Task Force on practice guidelines. Circulation. 2011;123(10):1144-1150.

55. Ansell J, Hirsh J, Poller L, Bussey H, Jacobson A, Hylek E. The pharmacology and management of the vitamin K antagonists: the Seventh ACCP Conference on Antithrombotic and Thrombolytic Therapy. Chest. 2004;126(Suppl 3):204S-233S.

56. Hylek EM, Singer DE. Risk factors for intracranial hemorrhage in outpatients taking warfarin. Ann Intern Med. 1994;120(11):897-902.

57. Odén A, Fahlén M, Hart RG. Optimal INR for prevention of stroke and death in atrial fibrillation: a critical appraisal. Thromb Res. 2006;117(5):493-499.

58. Stafford RS, Singer DE. National patterns of warfarin use in atrial fibrillation. Arch Intern Med. 1996;156(22):2537-2541.

59. Bungard TJ, Ghali WA, Teo KK, McAlister FA, Tsuyuki RT. Why do patients with atrial fibrillation not receive warfarin? Arch Intern Med. 2000;160(1):41-46.

60. Go AS, Hylek EM, Borowsky LH, Phillips KA, Selby JV, Singer DE. Warfarin use among ambulatory patients with nonvalvular atrial fibrillation: the anticoagulation and risk factors in atrial fibrillation (ATRIA) study. Ann Intern Med. 1999;131(12):927-934.

61. Samsa GP, Matchar DB, Goldstein LB, et al. Quality of anticoagulation management among patients with atrial fibrillation: results of a review of medical records from 2 communities. Arch Intern Med. 2000;160(7):967-973.

62. Turpie AG. New oral anticoagulants in atrial fibrillation. Eur Heart J. 2007;29(2):155-165.

63. Bates SM, Weitz JI. The status of new anticoagulants. Br J Haematol. 2006;134(1):3-19.

64. Olsson SB. Stroke prevention with the oral direct thrombin inhibitor ximelagatran compared with warfarin in patients with non-valvular atrial fibrillation (SPORTIF III): randomised controlled trial. Lancet. 2003;362(9397):1691-1698. 
65. Albers GW, Diener HC, Frison L, et al; SPORTIF Executive Steering Committee for the SPORTIF V Investigators. Ximelagatran vs warfarin for stroke prevention in patients with nonvalvular atrial fibrillation: a randomized trial. JAMA. 2005;293(6):690-698.

66. Hermans C, Claeys D. Review of the rebound phenomenon in new anticoagulant treatments. Curr Med Res Opin. 2006;22(3):471-481.

67. Fiessinger JN, Huisman MV, Davidson BL, et al; THRIVE Treatment Study Investigators. Ximelagatran vs low-molecular-weight heparin and warfarin for the treatment of deep vein thrombosis: a randomized trial. JAMA. 2005;293(6):681-689.

68. Connolly SJ, Ezekowitz MD, Yusuf S, et al; RE-LY Steering Committee and Investigators. Dabigatran versus warfarin in patients with atrial fibrillation. N Engl J Med. 2009;361(12):1139-1151.

69. Bousser MG, Bouthier J, Büller HR, et al. Comparison of idraparinux with vitamin $\mathrm{K}$ antagonists for prevention of thromboembolism in patients with atrial fibrillation: a randomised, open-label, non-inferiority trial. Lancet. 2008;371(9609):315-321.
70. Connolly SJ, Eikelboom J, Joyner C, et al; AVERROES Steering Committee and Investigators. Apixaban in patients with atrial fibrillation. N Engl J Med. 2011;364(9):806-817.

71. Patel MR, Mahaffey KW, Garg J, et al; ROCKET AF Investigators. Rivaroxaban versus warfarin in nonvalvular atrial fibrillation. $N$ Engl J Med. 2011;365(10):883-891.

72. Granger CB, Alexander JH, McMurray JJ, et al; ARISTOTLE Committees and Investigators. Apixaban versus warfarin in patients with atrial fibrillation. $N$ Engl J Med. 2011;365(11):981-992.

73. Merli G, Spyropoulos AC, Caprini JA. Use of emerging oral anticoagulants in clinical practice: translating results from clinical trials to orthopedic and general surgical patient populations. Ann Surg. 2009;250(2): 219-228.

74. Eerenberg ES, Kamphuisen PW, Sijpkens MK, et al. Reversal of rivaroxaban and dabigatran by prothrombin complex concentrate: a randomized, placebo-controlled, crossover study in healthy subjects. Circulation. 2011;124(14):1573-1579.

\section{Publish your work in this journal}

The Journal of Blood Medicine is an international, peer-reviewed, open access, online journal publishing laboratory, experimental and clinical aspects of all topics pertaining to blood based medicine including but not limited to: Transfusion Medicine; Blood collection, Donor issues, Transmittable diseases, and Blood banking logistics; Immunohematology; Artificial and alternative

\section{Dovepress}

blood based therapeutics; Hematology; Biotechnology/nanotechnology of blood related medicine; Legal aspects of blood medicine; Historical perspectives. The manuscript management system is completely online and includes a very quick and fair peer-review system. Visit http://www.dovepress.com/ testimonials.php to read real quotes from published authors.

Submit your manuscript here: http://www.dovepress.com/Journal-of-blood-medicine-journal 